\title{
ERP uygulama öncesi için süreç odaklı bir model önerisi ve testi $^{1}$
}

\section{A proposal and testing of a process-oriented model for ERP pre- implementation}

\author{
Gülay Ekren² \\ Aykut Hamit Turan ${ }^{3}$
}

${ }^{1}$ Bu çalışma, Prof. Dr. Aykut Hamit Turan danışmanlığında, Sakarya Üniversitesi İşletme Enstitüsünde yürütülen “İşletmeler için Çevik Illkelere Dayalı bir ERP Uygulama Metodunun Geliştirilmesi" başlıklı doktora tezinden türetilmiştir.

2 Doktora Öğrencisi, Sakarya Üniversitesi, Sakarya, Türkiye;

Öğr. Gör., Sinop Üniversitesi, Sinop, Türkiye, gekren@sinop.edu.tr

ORCID: 0000-0003-1226-7039

3 Prof. Dr., Sakarya Üniversitesi, Sakarya Türkiye, ahturan@sakarya.edu.tr

ORCID: 0000-0002-8855-4643

\section{Sorumlu Yazar/Corresponding Author:}

Gülay Ekren,

Sinop Üniversitesi, Sinop, Türkiye, gekren@sinop.edu.tr

Başvuru/Submitted: 2/01/2021

Revizyon/Revised: 28/02/2021

Kabul/Accepted: 5/03/2021

Yayın/Online Published: 25/03/2021

Atıf/Citation: Ekren, G., \& Turan, A. H., ERP uygulama öncesi için süreç odaklı bir model önerisi ve testi, bmij (2021) 9 (1): 137-154, doi:

https://doi.org/10.15295/bmij.v9i1.1740

Öz

Bu araştırmada, Yazılım Geliştirme Yaşam Döngüsü (SDLC) yaklaşımı ile ERP projelerinin uygulama öncesi aşaması için süreç odaklı bir model önerilmektedir. SDLC yaklaşımı Planlama, Analiz, Tasarım, Gerçekleştirme, Test \& Entegrasyon ve Bakım gibi sıralı ve doğrusal süreçler içermektedir. Araştırmanın amacı ERP uygulama öncesi aşamada SDLC'deki bir sürecin diğer bir süreci nasıl etkilediğini incelemek ve bu süreçler arasındaki ilişkileri test etmektir. Araştırmada, bir PLS-SEM (kısmi en küçük kareler yapısal eşitlik modellemesi) modeli önerilmiştir. Bu modelin geçerliliği ve güvenirliliği test edilmiştir. Model, SDLC'nin her süreci (değişkenler) için ayrı ayrı incelenmiş ve değişkenlerin birbirlerini ne ölçüde açıladığı, değişkenler arasında kurulan ilişkilerin model tarafından desteklenip desteklenmediği değerlendirilmiştir. Elde edilen bulgulara göre, Planlama süreci, Analiz sürecinde 0.74, Gerçekleştirme sürecinde 0.25, Test ve Entegrasyon sürecinde 0.35 birimlik pozitif yönde bir etkiye neden olmaktadır. Benzer şekilde Analiz süreci, Tasarım sürecinde 0.68 birimlik pozitif yönde bir etkiye neden olmaktadır. Tasarım süreci ise, Gerçekleștirme sürecinde 0.48 , Test \& Entegrasyon sürecinde 0.43 , Bakım sürecinde 0.53 birimlik pozitif yönde bir etkiye neden olmaktadır. Sonuç olarak ERP'nin uygulama öncesi aşamasındaki planlama süreci, sonraki süreçler açısından kritik öneme sahiptir. Benzer şekilde, analiz ve tasarım sürecindeki en iyi iş uygulamaları, kendilerinden sonra gelen gerçekleştirme, test \& entegrasyon ve bakım süreçlerini olumlu yönde etkilemektedir.

Anahtar Kelimeler: Bilişim Sistemleri, ERP, SDLC, Uygulama Öncesi, Süreç Yönetimi

Jel Kodlari: C20, L52, O33

\begin{abstract}
In this research, a process-oriented model for the pre-implementation phase of ERP projects was proposed with the Software Development Life Cycle (SDLC). SDLC approach includes sequential and linear processes such as Planning, Analysis, Design, Implementation, Test \& Integration, and Maintenance. The purpose of the research is to examine how a process in SDLC affects what came after another process during the pre-implementation phase of ERP and then test the relationships between them. In the study, a PLS-SEM (partial least squares structural equation modelling) model was proposed. The validity and reliability of the model were tested. The model was examined separately for each process (variables) of the SDLC and evaluated in such issues; to what extent the variables explained each other, the model supported the relationships between variables. According to the findings, the "Planning" process has a positive effect of 0.74 on the "Analysis" process as well as 0.25 on the "Implementation" process and 0.35 on the "Test \& Integration" process. Similarly, the "Analysis" process has a positive effect of 0.68 on the "Design" process. The "Design" process has a positive effect of 0.48 on the "Implementation" process as well as 0.43 in the "Test \& Integration" process and 0.53 in the "Maintenance" process. As a result, the "Planning" process in the preimplementation phase of ERP is critical in subsequent processes. Similarly, best business practices in the "Analysis" process as well as "Design" process positively affect the other processes such as "Implementation", "Test \& Integration", and "Maintenance".
\end{abstract}

Keywords: Information Systems, ERP, SDLC, Pre-implementation, Process Management

Jel Codes: C20, L52, O33

(C) 2021 The Author(s).

Bu makale, araştırma ve yayın etiğine uygun hazırlanmış ve iThenticate ile intihal taramasından geçirilmiştir. This article was prepared in line with research and publication ethics and scanned for plagiarism by using iThenticate. 


\title{
Extended Abstract
}

\section{A proposal and testing of a process-oriented model for ERP pre-implementation}

\begin{abstract}
Literature
Enterprise Resource Planning (ERP) systems are information systems that collect and store data in real-time. They facilitate the access of stored data to the different units in an organization by using a single database. Today, many businesses endure this costly and challenging process to transform the old systems into an ERP system. The ERP Life Cycle, generally called "ERP implementation", consists of three stages; pre-implementation, implementation, and post-implementation. Various studies examine the ERP implementation process from the Software Development Life Cycle (SDLC) in the literature. However, most of the studies focus more on the implementation and post-implementation phases of ERP implementation projects.
\end{abstract}

\section{Research subject}

In this research, a process-oriented model is proposed for the pre-implementation phase of ERP implementation projects with the SDLC approach.

\section{Research purpose and importance}

The purpose of the research is to examine and test how one of the SDLC processes affects another process, especially during the pre-implementation phase. The pre-implementation phase of ERP is critical in terms of subsequent phases.

\section{Contribution of the article to the literature}

The first phase of the ERP Life Cycle (pre-implementation) lacks theory support and data support in the literature. For this reason, this research focused on re-designing the pre-implementation phase of ERP projects according to the SDLC approach.

\section{Design and method}

\section{Research type}

This study is a quantitative study designed exploratory.

\section{Research problems}

SDLC follows a sequential and linear process. The life cycle of SDLC starts with the "Planning" process, continues with the "Analysis", "Design", "Implementation", "Test \& Integration" processes, and ends with "Maintenance". This study examined how a process affects what came after another process. In the literature, SDLC processes are not sufficiently understood or studied, especially for the pre-implementation phase of ERP projects. For this reason, first, the problem was discovered by collecting secondary data.

\section{Population and sampling}

The population consists of experts, project managers, implementation developers, software developers, consultants, and academicians experienced in ERP and have taken part in ERP implementation projects. The research sample consists of 212 people involved in ERP projects in Turkey for at least five years. The snowball sampling method was used to access them via the LinkedIn social network site.

\section{Data collection method}

At this stage, a measurement tool is developed to measure the research variables, and then it is designed a classification structure. Then this quantitative measurement tool is used in the quantitative data collection process. A five-point Likert type scaled survey used to measure the six observed variables, such as 1) Planning: PL, 2) Analysis: AN, 3) Design: TA, 4) Implementation: GE, 5) Test \& Integration: TE, 6) Maintenance: BA. PL includes nine items, AN includes five items, TA includes three items, and GE includes four items. Besides, TE, as well as BA, include four items, respectively.

\section{Research model}

A process-oriented model was introduced with the help of PLS-SEM. PLS-SEM is a statistical approach used to model complex multivariate relationships between observed and latent variables. The proposed model is a kind of reflective measurement model. Hypotheses were developed based on the model (Figure 1) and then tested to discover the relationships between the structures and their effective rates on each other.

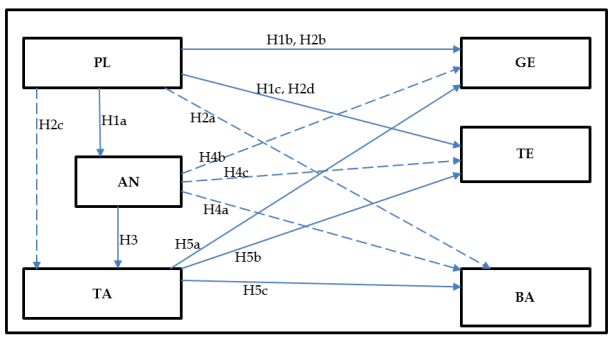

Figure 1: Research Model

\section{Research hypotheses}

H1a. PL process positively affects the AN process.

H1b. PL process positively affects the GE process.

H1c. PL process positively affects the TE process.

$\mathrm{H} 2 \mathrm{a}$. AN, as well as TA processes, have multiple mediating effects during the effect of the PL process on the BA process.

$\mathrm{H} 2 \mathrm{~b}$. AN, as well as TA processes, have multiple mediating effects during the effect of the PL process on the GE process. 
H2c. AN process has a mediating effect during the effect of the PL process on the TA process. H3. AN process positively affects the TA process.

H4a. TA process has a mediating effect during the effect of the AN process on the BA process.

$\mathrm{H} 4 \mathrm{~b}$. TA process has a mediating effect during the effect of the AN process on the GE process.

H4c. TA process has a mediating effect during the effect of the AN process on the TE process.

H5a. TA process positively affects the GE process.

H5b. TA process positively affects the TE process.

H5c. TA process positively affects the BA process.

\section{Quantitative analysis}

In order to show to what extent, the indicators reflecting the structures (observed variables) in the model, exploratory factor analysis was conducted through the SmartPLS 3.3.2 program. Then, to determine the validity and reliability of the measurement tool, path analysis, and parameter estimation of the model's structures were made. The estimated fit of variables in the proposed model was evaluated using the predictive accuracy criterion (R2), estimated correlation criterion (Q2), and effect size (f2) statistics.

\section{Findings and discussion}

\section{Findings as to the result of the analysis}

The factor loads of all indicators reflect each observed variable examined. The standard factor load of the indicators reflecting each observed variable is over 0.70 . In the measurement model, the composite reliability coefficients of all variables are above 0.80. The Cronbach Alpha value, which shows the internal consistency, was found to be above 0.80 . Convergent validity is sufficient as AVE values for all variables are above 0.50. Also, the measurement model has discriminant reliability as the HTMT values for all variables are below 0.90 .

$\mathrm{R}^{2}$ value gives the amount of variance explained by the independent variable $(\mathrm{PL})$. As a result, the PL process can explain the AN process at $54 \%$, the TA process at $47 \%$, the GE process at $44 \%$, the TE process at $50 \%$, and the BA process at $28 \%$. The $\mathrm{Q}^{2}$ value indicates whether the variables in the PLS-SEM path model are presumably suitable for the structure or not. As a result, variables such as PL, AN, GE, TE, and BA are presumably highly suitable for this model, while the TA variable is moderately suitable. According to the $\mathrm{f}^{2}$ analysis, which determines the effect size of the variables, the PL variable affects the AN variable at a high level; however, it does not affect GE and TE variables. Since the AN variable affects the TA variable at a high level, the TA variable moderately affects most variables such as GE, TE, and BA.

\section{Hypothesis test results}

Path analysis shows whether the relationships established through hypotheses are also accepted. The $t$ values of each hypothesis's path coefficient values are greater than 1.96 , which is the $t$ table value of the $95 \%$ confidence interval. H1a hypothesis in this model (Figure 2$)$ is accepted $(\beta=0.737, \mathrm{t}=19.195, \mathrm{p}<0.01)$ and the PL effects the AN positively. Similarly, the H1b hypothesis was accepted $(\beta=0.245, t=3.070, p<0.01)$ and the PL effects the GE positively. The H1c hypothesis was accepted $(\beta=0.348, t=4.821$, $p<0.01)$, and the PL effects the TE process positively. H3 hypothesis was accepted $(\beta=0.682, t=15.776, p<0.01)$ and the AN affect the TA positively. H5a hypothesis was accepted $(\beta=0.476, \mathrm{t}=6.251, \mathrm{p}<0.01)$, the TA effects the GE. H5b hypothesis was accepted $(\beta=0.433, t=6.271, p<0.01)$, the TA positively affects the TE. H5c hypothesis was accepted $(\beta=0.532, t=8.994, p<0.01)$, TA effects BA positively. Similarly, H4a, H4b, H4c, H2a, H2b, H2c, H2d hypotheses that examine the mediating effect between variables are accepted and statistically significant.

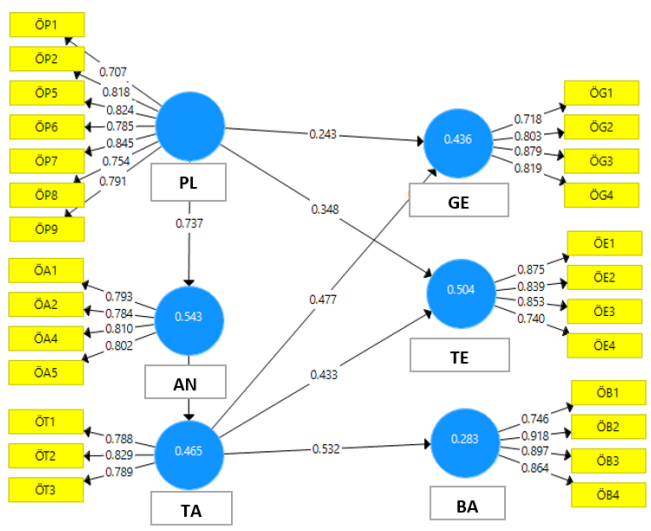

Figure 2: Visual Depiction of the Measurement Model

\section{Discussing the findings with the literature}

During the pre-implementation phase of ERP projects, the Planning process is critical. According to the findings, the Planning process before ERP implementation has a positive effect of 0.74 in the Analysis process, 0.25 in the Implementation process, and 0.35 in the Test \& Integration process. In the literature, it is possible to come across studies that the planning process's problems, which is the first stage of SDLC, affect the subsequent processes negatively (Hustad \& Olsen, 2011; Grenci \& Hull, 2020).

The Analysis process is also one of the most critical processes in ERP implementation projects. The design process, which comes after the Analysis process, is when the information gathered logically during the analysis (Marnewick \& Labuschagne, 2005; Mudiraj; 2017). According to the findings, the Analysis process has a positive effect of 0.68 in the Design Process. The design process has a positive effect of 0.48 in the Implementation process and 0.43 in the Test and Integration process, and 0.53 in the Maintenance process.

In the research, the mediating effect of Design and Analysis processes on other processes was also examined. According to the findings, the design process before ERP implementation has a partial mediation effect between Analysis and Maintenance, Analysis and Realization, Analysis and Test \& Integration processes. Similarly, Analysis and Design processes together have a 
partial mediation effect between planning and Maintenance, Planning and Implementation, Planning and Testing \& Integration. Also, the Analysis process lonely acts as a mediator between Planning and Design processes.

Conclusion, recommendation, and limitations

\section{Results of the article}

The ERP system's implementation phases are in line with traditional SDLC processes, and both approaches are used intertwined in ERP implementation projects. In this study, with the SDLC approach, a process-oriented model for business applications that should be carried out before ERP implementation is proposed, the validity and reliability of this model.

Suggestions based on results

This study has a lens for the pre-implementation phase of ERP projects. The pre-implementation phase, as the first phase of ERP implementation, has a critical impact on the overall success of ERP projects. In this framework, more research needs to conduct to explain the effect of SDLC on ERP implementation projects. Moreover, the proposed model in this study needs to test experimentally in a sectoral context.

\section{Limitations of the article}

Generally, there are three phases of ERP implementation, such as pre-implementation, implementation, and post-implementation. This study only focused on the pre-implementation phase. Similar studies should do for other phases. Besides, the sample of this study consists of only 122 people from different sectors. The number of people may vary on a sectoral basis. It was not possible to see these differences clearly in this study. The study needs to apply for a specific sector such as manufacturing, automotive, construction, metalworking, energy, mining, telecommunications, IT, retail, food, or beverage in future studies. 


\section{Giriş}

Kurumsal Kaynak Planlama (Enterprise Resource Planning, ERP) sistemleri, bir işletmenin tüm fonksiyonları ve birimleri arasında bilgi akışını kolaylaştıran, iş faaliyetlerini entegre eden ve yöneten yazılım mimarileri olarak tanımlanmaktadır (Huang, 2016, s. 224). ERP sistemleri genellikle, verileri gerçek zamanlı olarak toplayan ve depolayan tek bir veri tabanı kullanarak organizasyondaki farklı birimlerin bu verilere erişimini kolaylaştırmaktadır. ERP ile sağlanan potansiyel faydalar çok olduğundan (Kanellou ve Spathis, 2013, s. 213), yaklaşık son yirmi yıldır, birçok işletme hâlihazırda kullandıkları eski sistemleri bir ERP sistemine dönüştürmek için "ERP uygulaması (ERP implementation)" adı verilen bu zorlu ve maliyetli sürece katlanmaktadır (Ehie ve Madsen, 2005, s. 546; Panorama Consulting, 2020).

ERP uygulama süreci genelde, uygulama öncesi (pre-implementation), uygulama aşaması (implementation) ve uygulama sonrası (post-implementation) olmak üzere üç aşamadan oluşmaktadır (Huang, 2016, s. 225; Huang ve Yasuda, 2016, s. 7). Huang ve Yasuda (2016) ERP uygulamasinin ilk aşamasında üst düzey yöneticiler tarafından işletmenin bir ERP sistemi uygulayıp uygulamayacağına karar verildiğini, bu aşamada "Yazılım veya Sistem Geliştirme Yaşam Döngüsü" (Software or System Development Life Cycle, SDLC) kapsamında planlama, analiz, tasarım gibi süreçlerle karşılaşıldığını belirtmektedir. Huang ve Yasuda (2016) ayrıca bu süreçlerin uygulanacak ERP projesinin ilk aşamasında geliştirildiğini belirtmektedir. Benzer şekilde ERP uygulama modeli öneren diğer birçok çalışmada (Huang, 2016; Grenci ve Hull, 2020), geleneksel SDLC süreçlerinin ERP yaşam döngüsü içinde kullanıldığı görülmektedir. Huang'a (2016) göre geleneksel ERP Yaşam Döngüsü modellerinin, SDLC'ye benzer bir ERP uygulama yaşam döngüsü modeline benzeme olasıllı̆̆ yüksektir. Mudiraj'a (2017, s. 179) göre, ERP sistemleri, işletmelerin geleneksel iş süreçlerinden kaynaklanan hatalarını en aza indirmek amaciyla mevcut iş süreçlerini yüksek teknoloji ve ileri bilgi işlem yöntemleriyle yeniden yapılandırmaya olanak sağlayan ticari yazılım paketleridir. Literatürdeki bu çalışmalara benzer şekilde bu araştırmada da ERP uygulama sürecine SDLC mantığı ile bakılmaktadır. SDLC modeli temel olarak yeni bir yazılım geliştirmeye dayanan süreçler içermektedir. Bu süreçler, uygulanan metodolojiye göre değişmektedir, ancak çoğunlukla planlama, gereksinimlerin tanımlanması, analizi, yeni sistemin tasarımı, gerçekleştirme, bakım ve uygulama sonrası destek gibi süreçleri içermektedir (Balaji ve Murugaiyan, 2012).

ERP Yaşam Döngüsü ile ilgili araştırmalarda araştırma yöntemleri genelde süreç modeli çıkarımlarından oluşmaktadır. ERP yaşam döngüsünün süreç modelini oluştururken farklı yöntemler kullanılabilmektedir. Literatürde ERP sistemlerini "Enformasyon Sistemleri (Information Systems, IS)" bakış açısı ile değerlendiren geleneksel SDLC modelinin kullanılması (Grenci ve Hull, 2020), önceden tanımlanmış ERP Yaşam Döngüsü modellerinin değiştirilmesi (Bento ve Costa, 2013), süreç modelini oluşturmak için örnek olay veya ampirik verilere dayalı analizlerin kullanılması (Ahmad vd., 2012) gibi farklı yöntemlere rastlamak mümkündür. Ayrıca ERP uygulama sürecinin farklı aşamalarına odaklanan çalışmalara da rastlamak mümkündür (Peng ve Nunes, 2009; Huang, 2016; Mahmud vd., 2017). Ancak yukarıda bahsedilen çalışmaların çoğunda ERP uygulama projelerinin daha çok uygulama aşaması ve uygulama sonrası aşamalarına odaklanıldığı görülmektedir. Örneğin; Huang (2016), çalışmasında Japonya'da büyük ve küçük ölçekli işletmelerin ERP’ye geçişiyle ilgili 40 örnek olayı analiz etmiştir. Elde edilen bulgulara göre özellikle ERP Yaşam Döngüsünün uygulama sonrası aşamasında sistemin performans sorunlarının karar verme süreçlerine etkisi tartışılmıştır. Ruivo vd. (2014) çalışmalarında, ERP uygulama sonrası süreçlerin, işletmelerin performansının önemli bir belirleyicisi olduğunu savunmaktadır. Diğer yandan Huang ve Yasuda (2014) çalışmalarında 26 adet ERP Yaşam Döngüsü modelini incelemiş, bunların hepsinde ERP projelerinin uygulama öncesi aşamadan başladığı belirtilmektedir. Ayrıca ERP uygulama öncesi aşamanın bir karar verme aşaması olduğunu, bu aşamada işletmede ERP sisteminin henüz mevcut olmadığını ifade etmektedir (s. 75). ERP Yaşam Döngüsü ile ilgili ERP literatürü incelendiğinde, ERP uygulama öncesine yönelik bir araştırma boşluğu olduğu görülmektedir. Özellikle ERP Yaşam Döngüsünün ilk aşamasının teori desteğinden ve veri desteğinden yoksun olduğu görülmektedir. Bu nedenle bu araştırma ERP projelerinin uygulama öncesi aşamasına odaklanmaktadır.

$\mathrm{Bu}$ araştırmada SDLC yaklaşımıyla ERP uygulama projelerinin uygulama öncesi aşaması için süreç odaklı bir model önerilmektedir. Araştırmanın amacı ERP uygulama öncesi aşamada bir SDLC sürecinin diğer bir SDLC sürecini nasıl etkilediğini incelemek ve bu etkiyi test etmektir.

\section{Teorik çerçeve}

Dünyanın dört bir yanındaki işletmeler (Panorama Consulting, 2020), kendi organizasyonlarında tek tip bir enformasyon sistemi altyapısı kullanmak ve iş süreçlerini yeniden yapılandırmak gibi amaçlarla 
ERP sistemi uygulamalarını gerçekleştirmektedir. Bu uygulamalar bir organizasyon içindeki iş akışlarının ve süreçlerinin analizi ve tasarımı için 1990'lardan bu yana kullanılmaktadır (Davenport, 1990). Davenport'a (1990) göre bilgi teknolojileri ile iş süreçlerini yeniden yapılandırmanın (BPR, Business Process Reengineering) birlikte kullanılması yeni bir endüstri mühendisliği türü yaratma potansiyeline sahiptir. ERP sistemleri günümüzde tam da bu işi yapmaktadır. ERP sistemleri, bilgi teknolojilerini işletmelerin iş uygulamalarına uygun şekilde kullanmayı sağlamanın yanı sıra, iş süreçlerini yeniden yapılandıran bir mekanizmadır. ERP, bir işletmenin kurumsal yönetimine destek olurken, üretim, finans, tedarik zinciri ve dağıtım gibi birbirinden bağımsız çalışan bilgi sistemlerini entegre etmeyi amaçlamaktadır. Bu sistemler, işletmelerin mevcut bilgi sistemlerini değiştirmelerine izin vermekte ve ayrıca yönetim bilgi akışını standartlaştırmayı sağlamaktadır.

Yeniliklerin Yayılımı (Diffusion of Innovations) modeline göre yayılma, bir sosyal sistemin üyeleri arasında zaman içinde belirli kanallar aracılığıyla iletilen bir yeniliği içermektedir (Rogers, 2004). Kwon ve Zmud (1987) tarafından önerilen işletmelerdeki bilgi sistemi uygulamalarına yönelik süreç modeli; başlatma, benimseme, uyarlama, kabul, rutinleştirme ve içe aktarma şeklinde altı aşamadan oluşmaktadır. Kwon ve Zmud (1987) bu çalışmalarında Rogers'ın (2004) yeniliklerin yayılımı modelini kullanarak ERP uygulamaları ile ilgili çeşitli konuları ele almaktadır.

Bir IS metodolojisinin amacı, bir yazılım uygulamasının (örneğin, ERP gibi) başarılı bir şekilde geliştirilmesine veya uygulanmasına yardımcı olmaktır. İşletmeler, yazılım ihtiyaçlarını karşılama yönünde ilerlerken yazılım süreç modellerini (örneğin şelale modeli, V model, yinelemeli model, artımlı geliştirme modeli, evrimsel geliştirme modeli, sarmal model gibi) kullanmaktadır (Nizam, 2015, s. 4352). Geleneksel sistem geliştirme metodolojisi, sistem geliştirme süreci için doğrusal yaşam döngüsü adımlarını; planlama, analiz, tasarım, test, devreye alma şeklinde (Nizam, 2015, s. 45) açıkça tanımlamakta, dolayısıyla yazılım geliştirme süreçleri ile ilişkilendirilmektedir. Grenci ve Hull (2020) çalışmalarında ERP uygulamalarında SDLC modelini kullanmak amacıyla bir yaklaşım sunmaktadır. Grenci ve Hull'a (2020) göre ERP sistemlerine SDLC bakış açısı ile bakmak, sadece ERP uygulamalarına yönelik sorunlara çözüm bulmakla kalmamakta, SDLC'yi ERP uygulamalarında bir çerçeve olarak kullanmak için temel sunmaktadır. Diğer yandan Dearing ve Cox (2018, s. 184), yeniliklerin yayılımı modelini temel alan çalışmalarında yayılımın bir süreç olarak tanımlandığını, özellikle büyük ve karmaşık işletmelerde yeniliğin benimsenme zamanının ilk uygulamadan sonraki aşamalarda gerçekleştiğini belirtmektedir. Bu nedenle bu araştırma, ERP sistemlerine bir yazılım projesi gibi bakarak ERP uygulama öncesi aşama için süreç odaklı bir model önermektedir.

\section{Yöntem}

Bu araştırmada, SDLC'nin altı sıralı süreci (Planlama, Analiz, Tasarım, Gerçekleştirme, Test ve Entegrasyon, Bakım) için, ERP uygulama öncesi aşamada bir sürecin diğer bir süreci nasıl etkilediği, kısmi en küçük kareler yapısal eşitlik modellemesiyle (PLS-SEM) incelenmektedir. Öncelikle, literatür taraması yardımıyla bir araştırma modeli tasarlanmıştır. Tasarlanan modelde SDLC süreçleri, içsel gizil değişkenler olarak tanımlanmıştır. Değişkenler arasındaki ilişkileri test etmek amacıyla hipotezler geliştirilmiştir. Ayrıca önerilen modelin geçerliliği çeşitli uyum ölçütlerine göre değerlendirilmiştir.

PLS-SEM gözlenen ve gizil değişkenler arasındaki çok değişkenli karmaşık ilişkilerin modellenmesi için kullanılan istatistiksel bir yaklaşımdır. Ayrıca PLS-SEM daha çok keşif amaçlı araştırmalar için kullanılan, aynı zamanda açıklayıcı araştırmalar için de uygun görülen, tahmin odaklı bir yaklaşım olarak görülmektedir (Hair vd., 2017, s. 109; Çakır, 2019, s. 113). Bu araştırma keşif amaçlı bir araştırmadır. Araştırmada sunulan hipotezlerin açıklanması amaçlanmaktadır. Bu nedenle bu araştırmada PLS-SEM yaklaşımı kullanılmıştır. PLS-SEM, önerilen modelin analizinde çok değişkenli normal dağılım varsayımı gerektirmemektedir ve küçük hacimli örneklemlerde iyi performans sergilemektedir (Henseler vd., 2009; Hair vd., 2013; Yılmaz vd., 2019, s. 89).

Modelde yer alan yapılara ilişkin geçerlik ve güvenirlik analizleri, yol analizleri, parametre tahminleri, SmartPLS programı aracılığı ile gerçekleştirilmiştir. Araştırma kapsamında kullanılmak üzere bu programın SmartPLS 3.3.2 sürümü için akademik kullanım lisansı alınmıştır (Ringle vd., 2015).

\section{Araştırma modeli}

Önerilen araştırma modelinde yer alan değişkenler ve bu değişkenlere ait tanımlamalar aşağıda belirtildiği şekildedir (Nizam, 2015, s. 39-43):

- Planlama (PL): Proje hedeflerine ulaşmak için belirlenen süre ve mali kısıtlar dikkate alınarak izlenecek yöntemin, yapılacak işlerin, kullanılacak kaynakların ve iş takviminin belirlendiği SDLC sürecidir.

- Analiz (AN): Müşteriler tarafından sistemde gerçekleştirilmesi istenen temel görevlerin 
veya fonksiyonların ayrıntılı bir şekilde tanımlandığı SDLC sürecidir.

- Tasarım (TA): Bir önceki süreçte yapılan analizin, yazılım geliştirme araçlarının imkân ve sinırlılıkları dâhilinde geliştirilerek modellendiği SDLC sürecidir.

- Gerçekleştirme (GE): Tasarlanan modelin yazılım geliştirme araçları yardımıyla ürüne dönüştürüldüğü SDLC sürecidir.

- Test ve Entegrasyon (TE): Bu sürece kadar yapılanların gereksinimleri karşılayıp karşılamadığının kontrol edildiği SDLC sürecidir. Bu süreçte örneğin metot ve nesne seviyesinde birim testleri, bileşenler arası entegrasyon testleri, performans ve yük testleri, kullanıcı kabul testleri yapılmaktadır.

- Bakım (BA): Bu süreçte kullanıcı eğitimleri verilmekte, pilot uygulama ve nihai projenin uygulaması çalışmaları yapılmaktadır. Ayrıca projenin devreye (canlı kullanıma) alındığı, destek ve bakım çalışmalarının başlatıldığı SDLC sürecidir.

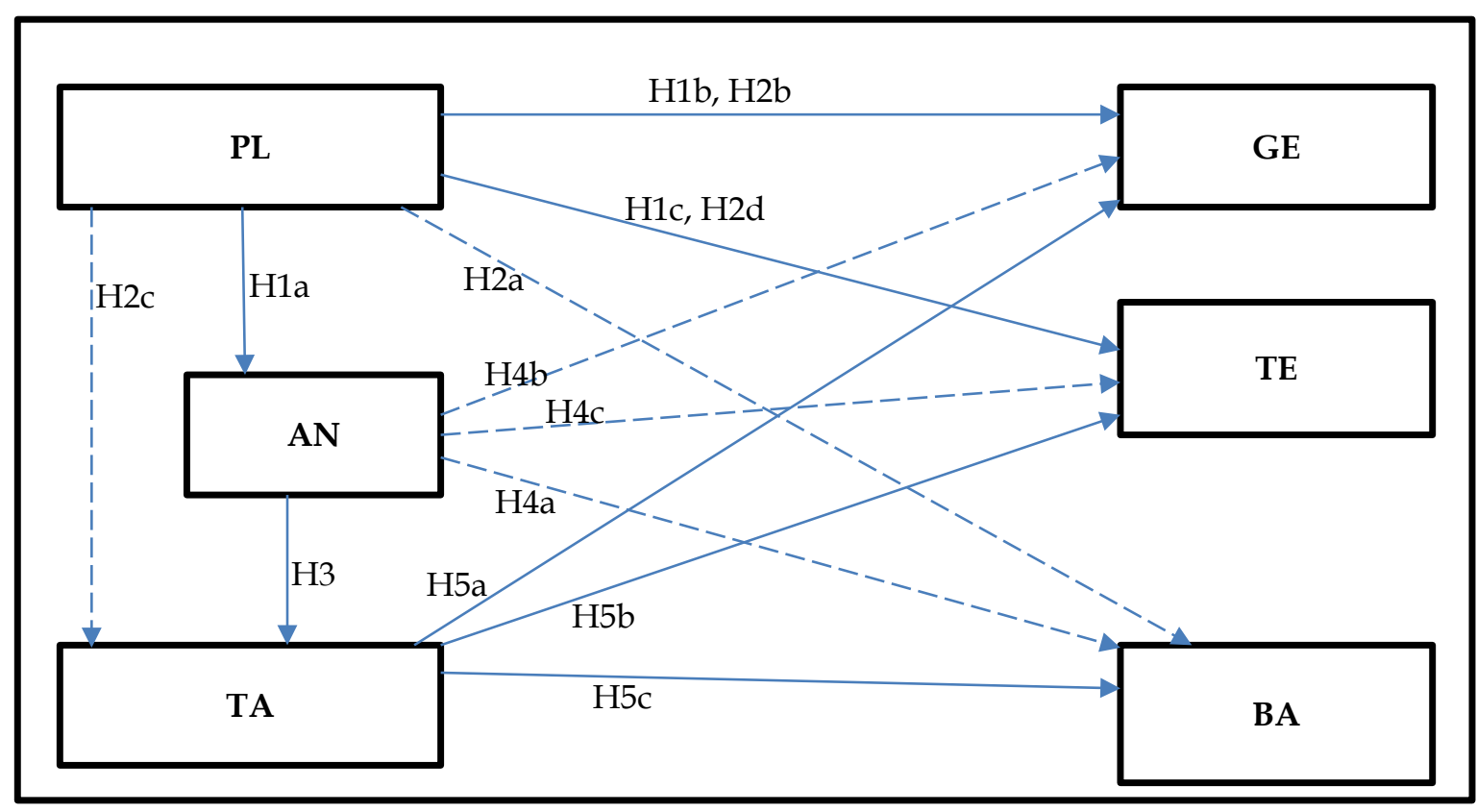

Şekil 1: Araştırmanın modeli

(PL: Planlama, AN: Analiz, TA: Tasarım, GE: Gerçekleştirme, TE: Test ve Entegrasyon, BA: Bakım)

Kaynak: Yazarlar tarafından üretilmiştir.

SDLC temel olarak sıralı ve doğrusal bir süreç izlemektedir. PL süreci ile başlayan yaşam döngüsü BA ile sonlandırılmaktadır. Bu araştırma SDLC'nin her bir sürecinin birbirleri ile ilişkili olduğu varsayımına dayanmaktadır. Araştırmada bir sürecin kendisinden sonra gelen diğer bir süreci nasıl etkilediği incelenmektedir. Şekil 1.'de araştırmada yer alan yapısal ilişkilerin kavramsal modellemesi yer almaktadır. Modelde yer alan değişkenler (her bir SDLC süreci) arasındaki ilişkiler ve değişkenlerin birbirlerine etki oranlarını keşfetmek amacıyla önerilen hipotezler aşağıda belirtildiği şekildedir.

\section{PL süreci ile diğer süreçler arasındaki ilişki}

PL süreci SDLC'nin başlangıç sürecidir. SAP'nin ASAP (Accelerated SAP) uygulama metodolojisinde proje hazırlık aşamasında projenin başlangıç planlaması yapılmakta, ardından gelen iş planı (business blueprint) aşamasında ise iş süreçlerinin tanımlanması ve AN süreci gerçekleştirilmektedir (Grenci ve Hull, 2020). Grenci ve Hull'e (2020) göre SDLC'nin ilk aşamalarında yaşanan problemler sonraki aşamaları da olumsuz yönde etkilemektedir. Örneğin PL sürecinde yaşanan bazı problemler; aşırı hırslı hedefler, bazı iş birimlerinin kapsam dışı tutulması, canlıya alma tarihinin kısaltılması, proje sırasında işlerin değiştirilmesi, projeye bağlılığın eksikliği gibi, AN sürecinde karmaşık gereksinimlerin oluşması, gereksinim hataları, yetersiz süreç analizi, zamanlama hataları gibi problemlere neden olabilmektedir. Devamında TA sürecinde yazılım hataları (bugs), yüksek düzeyde özelleştirme gereksinimleri, GE sürecinde konfigürasyon hataları, TE sürecinde diğer sistemler veya modüller arasında entegrasyon problemleri, başarısız testler veya test verileri ile canlıya geçilmesi gibi problemlere neden olabilmektedir. 
H1b. PL süreci, GE sürecini pozitif yönde etkiler.

H1c. PL süreci, TE sürecini pozitif yönde etkiler.

PL sürecinin SDLC'nin sonraki süreçlerini etkilediğine yönelik araştırmalara literatürde sıklıkla rastlanmaktadır. Hasibuan ve Dantes'e (2012, s. 3) göre ERP uygulama öncesi aşama, literatürde genellikle PL, adaptasyon veya TA süreci gibi alt süreçlere bölünmektedir. Bu çalışmada özellikle ERP uygulama öncesi aşamada proje hedeflerinin belirlenmesi, proje bütçesinin ve zamanının belirlenmesi, organizasyonun olgunluk seviyesinin belirlenmesi, bilgi teknolojilerine yatırımın değerlendirilmesi, mevcut bilgi sistemi altyapısının analizi gibi uygulamaların gerçekleştirildiğini belirtilmektedir. Capaldo ve Rippa (2009) ise çalışmalarında ERP uygulama aşaması başlamadan önce işletmenin teknik ve organizasyonel yeteneklerini analiz etmeyi ve bir işletme için en uygun uygulama stratejisini seçmeyi amaçlayan metodolojik bir yaklaşım önermektedir. Böylece bir sonraki uygulama aşamasında oluşabilecek sorunların tanımlanması ve yapılandırılması hedeflenmektedir. Meissonier ve Houze (2010, s. 541) işletme personelinin ERP sistemine yönelik bireysel ve grup direncinin ortaya çıkmasının ERP uygulama öncesi aşamada ortaya çıktığını savunmaktadır. Bu direnç baştan önlenmezse ERP uygulama sürecinin son aşamasına kadar devam etmektedir (Abdinnour ve Saeed, 2015). Chadhar ve Daneshgar (2018, s. 148) bu görüşü destekler nitelikte üst yönetimin ERP uygulama öncesinde işletme personelini PL ve özelleştirme (customization) sürecine dâhil etmesi gerektiğini belirtmektedir. Böylece ileride ortaya çıkabilecek yanlış anlaşılmaların veya problem durumlarının önlenebileceği düşünülmektedir.

H2a. PL sürecinin BA süreci üzerindeki etkisinde, AN ve TA süreçlerinin çoklu aracılık etkisi vardır.

H2b. PL sürecinin GE süreci üzerindeki etkisinde, AN ve TA süreçlerinin çoklu aracılık etkisi vardır.

H2c. PL sürecinin TA süreci üzerindeki etkisinde, AN sürecinin aracılık etkisi vardır.

H2d. PL sürecinin TE süreci üzerindeki etkisinde, AN ve TA süreçlerinin çoklu aracılık etkisi vardır.

\section{AN süreci ile diğer süreçler arasındaki ilişki}

SDLC'nin AN süreci bir ERP uygulaması için ilk ve en önemli süreçtir. Mudiraj (2017), organizasyonun mevcut durumunun, çalışma ortamının, ihtiyaçların, kaynakların, amaçların ve hedeflerin analizinin bu süreçte gerçekleştiğini belirtmektedir. Ayrıca AN sürecinden sonra gelen TA sürecini, toplanan bu farklı türdeki fonksiyonel ve modüler bilgilerin mantıksal olarak bir araya getirildiği süreç olarak değerlendirmektedir.

H3. AN süreci, TA sürecini pozitif yönde etkiler.

SDLC'nin AN süreci, PL sürecine benzer şekilde, kendisinden sonra gelen SDLC süreçlerini etkilemektedir. Balaji ve Murugaiyan’a (2012) göre TA sürecinden sonra gelen süreçlere geçmeden önce organizasyonun gereksinimleri net bir şekilde belirlenmeli ve analiz edilmelidir. ERP uygulama öncesi AN sürecinde, iş süreçlerinin yeniden tasarımı, sistemin yapısı ve değişiklik yönetimi gibi hususlar değerlendirilmektedir (Marnewick ve Labuschagne, 2005, s. 153). Bu süreçte bir ERP sisteminin yapısı, yazılım bileşenleri ve bu bileşenlerin birbirleriyle nasıl etkileşime girdiği belirlenmektedir. İşletmenin mevcut koşullarını anlamak için iş süreçleri analiz edilmekte, fonksiyonel ve teknik gereksinimler gözden geçirilmektedir. Mudiraj (2014), BPR sürecini ve organizasyonda ERP uygulama öncesi aşamadaki önemini vurgulayan çalışmasında, bir işletmede BPR uygulamasının iş süreçlerinin radikal bir şekilde yeniden tasarlanmasını gerektiren bir yöntem olduğunu belirtmektedir.

H4a. AN sürecinin BA süreci üzerindeki etkisinde, TA sürecinin aracılık etkisi vardır.

H4b. AN sürecinin GE süreci üzerindeki etkisinde, TA sürecinin aracılık etkisi vardır.

H4c. AN sürecinin TE süreci üzerindeki etkisinde, TA sürecinin aracılık etkisi vardır.

\section{TA süreci ile diğer süreçler arasındaki ilişki}

SDLC'nin üçüncü süreci olan TA sürecinin GE süreci üzerindeki etkisini tartışan Marnewick ve Labuschagne'e (2005) göre GE süreci, somut operasyonel süreçler ve bilgi sistemi desteği oluşturmak için ürünlerini TA sürecinden almaktadır.

H5a. TA süreci, GE sürecini pozitif yönde etkiler.

SDLC'nin TA süreci aslında bir önceki süreç olan AN sürecinden gelen temel bilgileri içermektedir. ERP uygulama sürecinin tamamına yön veren bu bilgiler ve gelecekte istenen bir durum için oluşturulan yeni tasarımların temellerini, ERP uygulama öncesi aşamada oluşturmaktadır (Marnewick ve Labuschagne, 2005, s. 153). Mudiraj (2017), ERP uygulamalarında bazı yazılım araçları kullanılarak oluşturulan tasarıma göre ERP sisteminin gerçekleştirildiğini belirtmektedir. Mudiraj'e (2017) göre 
ayrıca, TA sürecinden sonra gerçekleştirilen TE süreci önemli bir süreçtir ve bu süreçte ERP'nin organizasyonun fonksiyonel, yönetimsel ve operasyonel amaçlarına ne kadar uyduğu kontrol edilmektedir.

H5b. TA süreci, TE sürecini pozitif yönde etkiler.

TA sürecinin SDLC'nin son süreci olan BA süreci üzerinde de etkisi bulunmaktadır. Grenci ve Hull (2020), SDLC'nin BA sürecinde yaşanan problemlerin ortaya çıkmasını, çalışanların iyi eğitilmemiş olmaları, çalışanların değişime direnç göstermesi, deneyimli çalışanların istihdam edilmemesi, sisteme yeterli veri girişinin yapılmaması gibi nedenlere bağlamaktadır.

H5c. TA süreci, BA sürecini pozitif yönde etkiler.

\section{Evren ve örneklem}

Araştırmanın evrenini ERP konusunda deneyimli, ERP uygulama projelerinde görev almış ERP uzmanları, proje yöneticileri, proje sorumluları, uygulama geliştiriciler, yazılım geliştiriciler, danışmanlar ve akademisyenler oluşturmaktadır. Araştırmanın örneklemini araştırmaya gönüllü katılım sağlayan 212 kişiden oluşturmaktadır. Bu kişilere LinkedIn sosyal ağ sitesi üzerinden kartopu örnekleme yöntemiyle ulaşılmıştır. Kartopu örnekleme yönteminde evren üzerinden örnek alınacak bir çerçeve oluşturmak amacıyla, az bulunan bir evrende tanımlanmış birkaç üyeden evrenin diğer üyelerini tanımlamaları istenmektedir. İlk başta tanımlanan üyelerden diğerlerini tanımlamaları istenmekte ve örneklem sayısı artarak devam etmektedir. Bir süre sonra belirli isimler hep ön plana çıktığında örneklem belirleme süreci sonlandırılmaktadır (Handcock ve Gile, 2011, s. 369).

Katılımcıların, uygulamasını gerçekleştirdikleri ERP sistemi ve ilgili işletmeye yönelik tanımlayıcı istatistikler Tablo 1.'de yer almaktadır.

Tablo 1. Katılımcılara ait tanımlayıcı istatistikler

\begin{tabular}{|c|c|c|c|c|c|}
\hline \multicolumn{3}{|c|}{ ERP konusundaki mesleki deneyiminiz nedir? } & \multicolumn{3}{|l|}{ ERP projesindeki göreviniz nedir? } \\
\hline Özellikler & Siklık & $\begin{array}{l}\% \mathrm{~N} \\
(212)\end{array}$ & Özellikler & S1klık & $\begin{array}{l}\% \mathrm{~N} \\
(212)\end{array}$ \\
\hline 1 yildan az & 2 & 0,9 & ERP Proje Yöneticisi & 90 & 42,5 \\
\hline $1-3$ yıl & 23 & 10,8 & ERP Modül Danışmanı & 26 & 12,3 \\
\hline $4-6$ y1l & 45 & 21,2 & $\begin{array}{l}\text { ERP Proje Danışmanı veya Uygulama } \\
\text { Danışmanı }\end{array}$ & 26 & 12,3 \\
\hline $7-9$ y1l & 46 & 21,7 & ERP Yazılım Geliştirici & 38 & 17,9 \\
\hline \multirow{2}{*}{10 yıl ve üstü } & \multirow{2}{*}{96} & \multirow{2}{*}{45,3} & ERP Uzmanı & 20 & 9,4 \\
\hline & & & Diğgr $^{* * *}$ & 12 & 5,6 \\
\hline \multicolumn{3}{|c|}{$\begin{array}{l}\text { Uyguladığınız ERP sistemi hangi mimariye } \\
\text { uyuyor? }\end{array}$} & \multicolumn{3}{|c|}{ ERP projesini gerçekleştirdiğiniz işletmenin büyüklüğü nedir? } \\
\hline Özellikler & S1klık & $\begin{array}{l}\% \mathrm{~N} \\
(212)\end{array}$ & Özellikler & S1klık & $\begin{array}{l}\% \mathrm{~N} \\
(212)\end{array}$ \\
\hline Tier I & 98 & 46,2 & Mikro işletme $\left(<10^{*}\right)$ & 2 & 0,9 \\
\hline Tier II & 48 & 22,6 & Küçük ölçekli işletme $\left(<50^{*}\right)$ & 10 & 4,7 \\
\hline \multirow{2}{*}{ Tier III } & \multirow{2}{*}{66} & \multirow{2}{*}{31,1} & Orta ölçekli işletme $\left(<250^{*}\right)$ & 37 & 17,5 \\
\hline & & & Büyük ölçekli işletme $\left(>250^{*}\right)$ & 163 & 76,9 \\
\hline \multicolumn{6}{|c|}{ ERP projesini gerçekleştirdiğiniz işletme hangi sektörde faaliyet göstermektedir? } \\
\hline Özellikler & Sıklık & $\begin{array}{l}\% \mathrm{~N} \\
(212)\end{array}$ & Özellikler & Siklık & $\begin{array}{l}\% \mathrm{~N} \\
(212)\end{array}$ \\
\hline İmalat & 36 & 17 & Yiyecek İçecek & 13 & 6,1 \\
\hline Otomotiv & 22 & 10,4 & Taşımacılık/Lojistik & 10 & 4,7 \\
\hline İnşaat & 17 & 8 & Perakende & 18 & 8,5 \\
\hline $\mathrm{IT}^{* *}$ & 16 & 7,5 & Petrokimya/İlaç & 11 & 5,2 \\
\hline Metal İşleme & 13 & 6,1 & Havacilık ve Savunma & 8 & 3,8 \\
\hline Madencilik & 6 & 2,8 & Mobilya ve Dekorasyon & 7 & 3,3 \\
\hline Enerji & 9 & 4,2 & Telekomünikasyon & 5 & 2,4 \\
\hline Tekstil & 9 & 4,2 & Diğer $* * * *$ & 12 & \\
\hline \multicolumn{6}{|c|}{$\begin{array}{l}\text { *İsletmede çalışan kişi sayısı } \\
* * \text { IT: Information Technology (Bilgi Teknolojisi) } \\
\text { ***ERP departman sorumlusu, ERP iş analisti, ERP proje mühendisi, ERP entegrasyon kalite sorumlusu, İK müdürü vs. } \\
\text { ****Tarım, Ormancılık, Avcılık, Balıkçlık, Eğitim, Finans ve Sigorta, Sağlık Hizmetleri, Kâğıt ve Ambalaj vb. }\end{array}$} \\
\hline
\end{tabular}

Katılımcıların \%45,3'ünün ERP konusunda 10 yıl ve üzeri mesleki deneyimi varken, yaklaşık \%77'si büyük ölçekli işletmelerde daha çok Tier I mimarisine sahip $(\% 46,2)$ ERP uygulama projelerinde yer almışlardır. Katılımcıların \%42,5'i, ERP proje yöneticisidir. Katılımcıların görev aldığ 1 ERP projelerinin $\% 17^{\prime}$ si imalat sektöründe, \%10,4'ü otomotiv sektöründe yer alan işletmelerde uygulanmaktadır (Tablo 1). 


\section{Veri toplama araçları}

Önerilen modelde yer alan altı gözlenen değişkeni (PL, AN, TA, GE, TE, BA) ölçmek amacıyla geliştirilen bir anket kullanılmıştır. Araştırmanın veri toplama süreci, kişiselleştirilmiş bir çevrimiçi anket aracilığıyla, 15 Ekim-30 Aralık 2019 tarihleri arasında gerçekleştirilmiştir.

Ankette yer alan maddeler beşli Likert tipi bir ölçek (1=kesinlikle katılmıyorum, 2=katılmıyorum, $3=$ kararsızım, 4=katılıyorum, 5=tamamen katılıyorum) yardımıyla ölçülmüştür. PL değişkeni, işletme ile proje arasındaki ilişkiyi anlamaya çalışan dokuz madde kullanılarak ölçülmektedir. AN değişkeni, proje kapsamının paydaşlar tarafından detaylandırılmasına odaklanan beş madde içermektedir. TA değişkeni, modüller ile sistem arasındaki ilişkiyi anlamaya çalışan üç maddeden oluşmaktadır. GE değişkeni, uygulamanın gerçekleştirileceği ortama yönelik hazırlıklara yönelik dört madde içermektedir. TE değişkeni, test araçları ve test ekibine yönelik hazırlık sürecini içeren dört maddeden oluşmaktadır. BA değişkeni ise bakım süreçlerine ilişkin dört madde içermektedir. Bu değişkenler ve değişkenlere ilişkin maddeler Tablo 2.'de yer almaktadır.

Tablo 2. Değişkenler ve değişkenleri temsil eden göstergeler

\begin{tabular}{|c|c|}
\hline \multicolumn{2}{|l|}{ D1: PL } \\
\hline ÖP1 & $\begin{array}{l}\text { Proje kapsamının belirlenmesi (Örneğin temel ihtiyaç alanlarının ve sınırların belirlenmesi, hangi modüllerin } \\
\text { uygulamaya ekleneceğinin belirlenmesi vs.) }\end{array}$ \\
\hline ÖP2 & İşletmenin projeden genel beklentilerinin ortaya konulması \\
\hline ÖP5 & İşletmenin gereksinimlerinin ve/veya ana hedeflerinin belirlenmesi \\
\hline ÖP6 & Projede yer alacak departmanlardan sorumlu kişilerin (anahtar kullanıcılar) belirlenmesi \\
\hline ÖP7 & Projenin ana hedeflerine uygun bir yönetim planının yapılması \\
\hline ÖP8 & İşletmede mevcut bilgi işlem altyapısının proje için uygunluğunun tespit edilmesi \\
\hline ÖP9 & İşletme içindeki temel iş süreçlerinin çıkartılması \\
\hline \multicolumn{2}{|r|}{ 要 } \\
\hline ÖA1 & $\begin{array}{l}\text { Farklı uzmanlık alanlarından paydaşların proje analiz toplantısına dahil edilmesi (Örneğin proje yöneticisi, } \\
\text { yazılım geliştirici, iş analisti, ürün yöneticileri, anahtar kullanıcılar, ERP danışmanları gibi) }\end{array}$ \\
\hline ÖA2 & $\begin{array}{l}\text { Proje kapsamını detaylandıran kararların alınması (Örneğin finans işlemlerinde Genel Muhasebe ve Borçlar } \\
\text { Muhasebesi modüllerinin kullanılması, Alacaklar Muhasebesinin mevcut satış programı ile entegre çalışması } \\
\text { gibi) }\end{array}$ \\
\hline ÖA4 & $\begin{array}{l}\text { Departman sorumlularının mevcut iş süreçlerine dair ERP yazılımından beklentileri doğrultusunda mevcut iş } \\
\text { süreçlerinin revize edilmesi (Örneğin eskisinde ne yapılıyordu? Şimdi ne yapılacak? planlamasının yapılması) }\end{array}$ \\
\hline ÖA5 & Proje ekibindeki her bir bireyin sorumluluklarının (görev tanımlarının) belirlenmesi \\
\hline \multicolumn{2}{|r|}{ he } \\
\hline ÖT1 & İmplementasyon için en uygun sistem gereksinimlerinin belirlenmesi \\
\hline ÖT2 & $\begin{array}{l}\text { Modüller arası ilişkiler göz önüne alınarak hiyerarşi planlamasının yapılması (Örneğin modül bazında iş } \\
\text { süreçleri ile ilgili akış diyagramları, örnek senaryoların hazırlanması vs.) }\end{array}$ \\
\hline ÖT3 & Kullanıcı ara yüzü tasarımıyla ilgili standartların belirlenmesi \\
\hline \multicolumn{2}{|r|}{ ( ) } \\
\hline ÖG1 & Uygulamanın kurulacağı ortamların (makineler, işletim sistemi vb.) hazırlanması \\
\hline ÖG2 & Yazilım geliştirme ekibinin kurulması \\
\hline ÖG3 & $\begin{array}{l}\text { Uygulamada yazılacak modüllerdeki geliştirme maddelerine sorumlu kişi (geliştirme ekibinden) atamalarının } \\
\text { yapılması }\end{array}$ \\
\hline ÖG4 & Geliştirme maddelerine yönelik zaman planlamasının yapılması \\
\hline \multicolumn{2}{|r|}{ 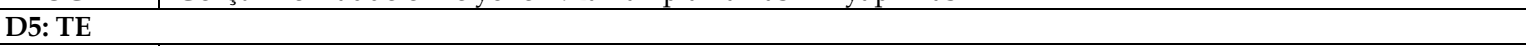 } \\
\hline ÖE1 & Her bir modül bazında test ekibinin oluşturulması \\
\hline ÖE2 & ERP sistemi ile entegre çalışacak ve test edilmesi gereken sistemlerin belirlenmesi \\
\hline ÖE3 & $\begin{array}{l}\text { Farklı test grupları için gerekli test araçlarının belirlenmesi (örneğin kodlama testleri, ekran testleri, kullanıcı } \\
\text { kabul testleri vs.) }\end{array}$ \\
\hline ÖE4 & $\begin{array}{l}\text { Canlı kullanıma geçiş planının yapılması (Örneğin yeni sistemin kullanılmaya başlanacağı tarih, öncesinde } \\
\text { yapılması gerekenler, eski programlardan veya sistemlerden verilerin aktarım tarihlerinin belirlenmesi vs.) }\end{array}$ \\
\hline \multicolumn{2}{|r|}{ 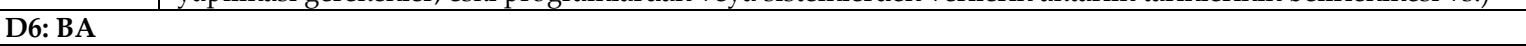 } \\
\hline ÖB1 & $\begin{array}{l}\text { Bakım-destek hizmetinin doğrudan yazılım tedarikçisinden mi yoksa partner firma üzerinden mi alınacağına } \\
\text { karar verilmesi }\end{array}$ \\
\hline ÖB2 & Bakım ekibinin oluşturulması \\
\hline ÖB3 & Bakım süreçlerine ilişkin iş birimlerinin bilgilendirilmesi \\
\hline ÖB4 & Canlı kullanıma geçiş ve/veya canlı kullanım sonrası bakım aşamalarının planlanması \\
\hline
\end{tabular}

Kaynak: Yazarlar tarafından üretilmiştir.

Tablo 3.'deki ölçek için SmartPLS 3.3.2 programı aracılığı ile keşfedici faktör analizi yapılmıştır. Böylelikle her bir gözlenen değişkeni yansıtan göstergelerin (indikatörlerin) faktör yükleri belirlenmiştir. Faktör yükleri, indikatörlerin temsil ettiği yapıları (değişkenleri) ne derecede yansıttığını göstermektedir. Bu oranın 0.70'in üzerinde olması tercih edilmektedir (Hair vd., 2011; Wong, 2013). Bu modelde kullanılan her bir gözlenen değişkeni yansıtan indikatörün standart faktör yükü $0.70^{\prime}$ in üstündedir (Tablo 3). Faktör yükleri 0.70 'in altında kalan üç indikatör (PL boyutundan iki adet, AN boyutundan bir adet) temsil ettikleri yapıyı yansıtmadıkları düşünüldüğünden listeden çıkarılmıştır. Gözlenen değişkenlere ait faktör yükleri Tablo 3.'te gösterilmektedir. 
Önerilen model bir yansıtıcı ölçüm modelidir. Yansıtıcı ölçüm modeli, bir yapıyı yansıtan okların yönünün yapıdan göstergeye doğru olduğu (açık değişken), ve yapının, göstergenin ölçüm modeline (ortak değişkenliğe) neden olduğu varsayımına dayanan bir ölçüm modelidir (Afthanorhan, 2014, s. 34).

Tablo 3. Gözlenen değişkenlere ait faktör yükleri ve tanımlayıcı istatistikler

\begin{tabular}{|c|c|c|c|c|}
\hline & Faktör Yükü ${ }^{* * *}$ & $\begin{array}{c}\text { Standart } \\
\text { Sapma }\end{array}$ & $t^{* *}$ & $\mathbf{p}^{*}$ \\
\hline \multicolumn{5}{|l|}{ PL } \\
\hline ÖP1 & 0.707 & 0.050 & 14.182 & 0.000 \\
\hline ÖP2 & 0.818 & 0.027 & 29.951 & 0.000 \\
\hline ÖP5 & 0.824 & 0.024 & 34.138 & 0.000 \\
\hline ÖP6 & 0.785 & 0.031 & 25.133 & 0.000 \\
\hline ÖP7 & 0.845 & 0.026 & 32.852 & 0.000 \\
\hline ÖP8 & 0.754 & 0.041 & 18.576 & 0.000 \\
\hline ÖP9 & 0.791 & 0.042 & 18.997 & 0.000 \\
\hline \multicolumn{5}{|l|}{ AN } \\
\hline ÖA1 & 0.793 & 0.033 & 23.885 & 0.000 \\
\hline ÖA2 & 0.784 & 0.032 & 24.475 & 0.000 \\
\hline ÖA4 & 0.810 & 0.031 & 26.397 & 0.000 \\
\hline ÖA5 & 0.802 & 0.035 & 23.179 & 0.000 \\
\hline \multicolumn{5}{|l|}{ TA } \\
\hline ÖT1 & 0.788 & 0.031 & 25.573 & 0.000 \\
\hline ÖT2 & 0.829 & 0.024 & 34.526 & 0.000 \\
\hline ÖT3 & 0.789 & 0.038 & 20.820 & 0.000 \\
\hline \multicolumn{5}{|l|}{ GE } \\
\hline ÖG1 & 0.718 & 0.058 & 12.352 & 0.000 \\
\hline ÖG2 & 0.803 & 0.046 & 17.406 & 0.000 \\
\hline ÖG3 & 0.879 & 0.025 & 35.859 & 0.000 \\
\hline ÖG4 & 0.819 & 0.030 & 27.633 & 0.000 \\
\hline \multicolumn{5}{|l|}{ TE } \\
\hline ÖE1 & 0.875 & 0.020 & 43.826 & 0.000 \\
\hline ÖE2 & 0.839 & 0.029 & 29.335 & 0.000 \\
\hline ÖE3 & 0.853 & 0.023 & 36.940 & 0.000 \\
\hline ÖE4 & 0.740 & 0.039 & 18.876 & 0.000 \\
\hline \multicolumn{5}{|l|}{ BA } \\
\hline ÖB1 & 0.746 & 0.042 & 17.827 & 0.000 \\
\hline ÖB2 & 0.918 & 0.015 & 59.778 & 0.000 \\
\hline ÖB3 & 0.897 & 0.016 & 54.666 & 0.000 \\
\hline ÖB4 & 0.864 & 0.024 & 35.984 & 0.000 \\
\hline \multicolumn{5}{|c|}{ 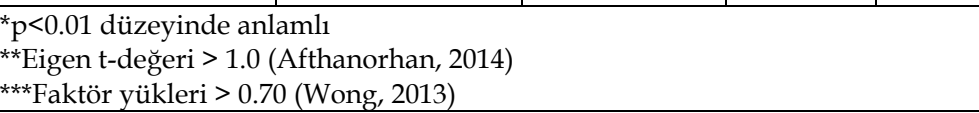 } \\
\hline
\end{tabular}

Modeldeki değişkenlerin bileşik güvenilirlik (Composite Reliability-CR) ve geçerlilik katsayılarına bakılmıştır. Tüm değişkenlerin $\mathrm{CR}$ katsayıları $0.80^{\prime}$ in üzerindedir (Tablo 3). Bileşik güvenirlik katsayısının 0.80 veya üzerinde bir değer olması beklenmektedir (Brunner ve SüB, 2005, s. 235). Benzer şekilde ölçüm modelinin içsel tutarlılığını gösteren Cronbach Alpha değerinin 0.70'den büyük olması beklenmektedir (Fink ve Litwin, 1995). Bu modeldeki değişkenler için elde edilen Cronbach Alpha değeri 0.80 'in üzerinde bulunmuştur (Tablo 4). Bu sonuca göre araştırmada kullanılan ölçeğin içsel tutarlılı̆̆ının yeterli seviyede olduğu söylenebilir.

Diğer yandan değişkenlerin yakınsama geçerliliği, açıklanan ortalama varyans (Average Variance Extracted-AVE) katsayısı ile test edildiğinde, AVE değeri 0.50' nin üstünde bir değer olmalıdır (Hair vd., 2011; Wong, 2013). Modelde yer alan tüm değişkenler için AVE değerleri 0.50'nin üzerindedir (Tablo 4). Tablo 3.'te yer alan Rho_A katsayısı, veri tutarlılığını görebilmek için hesaplanan bir katsayıdır. Bu katsayı değerinin 0.70 'in üzerinde olması faktör öğelerinin güvenilir olduğunu göstermektedir (Çakır, 2019, s. 117). Önerilen model için faktör öğeleri güvenilir bulunmuştur. 
Tablo 4. Yapısal güvenilirlik ve geçerlilik analizi

\begin{tabular}{|l|c|c|c|c|}
\hline & CA & Rho_A & CR & AVE \\
\hline PL & 0.899 & 0.905 & 0.921 & 0.625 \\
\hline AN & 0.809 & 0.811 & 0.875 & 0.636 \\
\hline TA & 0.724 & 0.727 & 0.844 & 0.643 \\
\hline GE & 0.821 & 0.838 & 0.881 & 0.651 \\
\hline TE & 0.846 & 0.854 & 0.897 & 0.686 \\
\hline BA & 0.881 & 0.907 & 0.918 & 0.738 \\
\hline CR: Composite Reliability, AVE: Average Variance Extracted, \\
CA: Cronbach's Alpha, Rho_A: Reliability Coefficient \\
\hline
\end{tabular}

Ayrışma geçerliliği için, her bir gizil değişkenin AVE değerlerinin karekökünün diğer değişkenlerle olan korelâsyonlarından daha büyük olması (Fornell-Larcker kriteri) ve gösterge yüklerinin tüm çapraz yüklerinden daha yüksek olması beklenmektedir (Fornell ve Larcker, 1981). Bu model, Fornell-Larcker kriteri için ayrışma geçerliliğini sağlamaktadır (Tablo 5). Ayrışma geçerliliğinin test edilmesi ayrıca Henseler vd. (2009) tarafından önerilen HTMT (Heterotrait-Monotrait Ratio) kriterine bakılarak da yapılabilmektedir. Korelasyonların HTMT değeri, PLS-SEM'de ayırt edici geçerliliği değerlendirmek amacıyla kullanılan bir yöntemdir. Henseler vd.'e (2009) göre HTMT değerlerinin 0.90' 1 altında olması beklenmektedir. Modelde yer alan tüm değişkenler için HTMT değerleri 0.90'ın altındadır. Bu sonuca göre modelde ayrışma geçerliliği sağlanmıştır (Tablo 5).

Tablo 5. Ayrışma geçerliliği için Fornell-Larcker ve HTMT analizi

\begin{tabular}{|c|c|c|c|c|c|c|}
\hline \multicolumn{7}{|c|}{ Fornell-Larcker Analizi } \\
\hline Değişkenler & AN & BA & GE & PL & TA & TE \\
\hline AN & $0.797^{*}$ & & & & & \\
\hline $\mathrm{BA}$ & 0.421 & $0.859 *$ & & & & \\
\hline$\overline{G E}$ & 0.547 & 0.461 & $0.807^{*}$ & & & \\
\hline PL & 0.737 & 0.369 & 0.550 & $0.790^{*}$ & & \\
\hline TA & 0.682 & 0.532 & 0.634 & 0.645 & $0.802^{*}$ & \\
\hline TE & 0.716 & 0.554 & 0.562 & 0.628 & 0.658 & $0.828^{*}$ \\
\hline \multicolumn{7}{|c|}{ HTMT Analizi } \\
\hline BA & 0.475 & & & & & \\
\hline$\overline{\mathrm{GE}}$ & 0.661 & 0.528 & & & & \\
\hline $\mathrm{PL}$ & 0.859 & 0.398 & 0.621 & & & \\
\hline TA & 0.881 & 0.651 & 0.806 & 0.789 & & \\
\hline TE & 0.864 & 0.618 & 0.654 & 0.711 & 0.833 & \\
\hline
\end{tabular}

\section{Bulgular}

\section{Değişkenlerin modele tahmini uyumu}

Önerilen modeldeki değişkenlerin modele tahmini uyumu; tahmin doğruluğu kriteri $\left(R^{2}\right)$, tahmini ilişki kriteri $\left(\mathrm{Q}^{2}\right)$ ve etki boyutu $\left(\mathrm{f}^{2}\right)$ istatistikleri kullanılarak değerlendirilmiştir (Kline, 2015). $\mathrm{R}^{2}$, modelde yer alan değişkenlerin birbirlerini ne ölçüde açıkladığını gösteren bir değerdir. $\mathrm{R}^{2}$ önerilen modeldeki bağımsız değişken (PL) tarafından gizil değişkenlerin açıklanan varyans miktarını vermektedir. $\mathrm{R}^{2}$ 'nin 0.26 'nın üzerinde olması beklenmektedir (Çakır, 2019). Önerilen modeldeki $\mathrm{R}^{2}$ değeri; AN değişkeni için 0.543, TA değişkeni için 0.465; GE değişkeni 0.436 , TE değişkeni için 0.504 ve BA değişkeni için 0.283 olarak bulunmuştur. Bunun anlamı önerilen modelde, PL süreci AN sürecini \%54 oranda, TA sürecini $\% 47$ oranda, GE sürecini $\% 44$ oranda, TE sürecini $\% 50$ oranda açılayabilirken, BA sürecini $\% 28$ oranda açıklayabilmektedir.

Önerilen yapısal modelin değerlendirilmesinde değişkenlerin tahminen uygunluğunu veya gücünü ölçmek için $\mathrm{R}^{2}$ değerine ek olarak Stone-Geisser' in $\mathrm{Q}^{2}$ değeri kullanılmıştır. Belirli bir içsel gizil değişken için sıfırdan büyük bir $\mathrm{Q}^{2}$ değeri, PLS-SEM yol (path) modelinde bir değişkenin yapı için tahminen uygun olup olmadığını göstermektedir (Hair vd., 2011). Aynı zamanda $\mathrm{Q}^{2}$ değeri, gizil değişkenlerin tahmin edicilik değerini vermektedir. Değişkenler arasındaki tahminen uygunluk düzeyini belirlerken $\mathrm{Q}^{2}$ değeri 0.02 ile 0.14 aralığında ise küçük, 0.15 ile 0.34 aralığında ise orta ve 0.35 'ten büyük ise yüksek düzeyde tahminen uygunluk olduğu söylenebilir (Hair vd., 2017).

$\mathrm{Q}^{2}$ değerini hesaplamak için Blindfolding yöntemi kullanılmıştır (Ringle vd., 2015). Blindfolding, örneklemin yeniden kullanımına yönelik bir tekniktir. PLS-SEM yol modelinin çapraz geçerliliği adına bir tahmin ilişkisi oluşturmak için bir değerlendirme kriteri olan Stone-Geisser'in $\mathrm{Q}^{2}$ değerinin (Stone, 1974; Geisser, 1974) hesaplanmasını sağlar. Bu çalışmada Blindfolding analizi ile elde edilen Q2 değerleri sırasıyla; PL için 0.495, AN için 0.392, TA için 0.289, GE için 0.411, TE için 0.472, ve BA için 
0.561 olarak bulunmuştur. Elde edilen $\mathrm{Q}^{2}$ değerlerine göre model geçerliliği sağlanmıştır. TA değişkeninin bu modele tahminen orta düzeyde uygun olduğu görülmektedir. Diğer yandan, TA dışındaki tüm diğer değişkenler bu modele tahminen yüksek derecede uyumludur.

Değişkenlerin birbirine etki boyutunu değerlendirmek amacıyla yapılan $\mathrm{f}^{2}$ analizi sonuçlarına göre; PL dışsal gizil değiş̧keni, aracı içsel gizil değişkeni olan AN değişkenini yüksek düzeyde etkilerken $\left(\mathrm{f}^{2}=1.188, \mathrm{p}<0.01\right)$, GE ve TE içsel gizil değişkenlerini etkilememektedir $\left(\mathrm{f}^{2}<0.15\right)$. Benzer şekilde AN değişkeni, modeldeki diğer aracı içsel gizil değişkeni olan TA değişkenini yüksek düzeyde etkilemektedir $\left(\mathrm{f}^{2}=0.868, \mathrm{p}<0.01\right)$. Diğer yandan TA değişkeni, GE değişkenini $\left(\mathrm{f}^{2}=0.236, \mathrm{p}<0.05\right), \mathrm{TE}$ değişkenini $\left(\mathrm{f}^{2}=0.221, \mathrm{p}<0.05\right)$ ve $\mathrm{BA}$ değişkenini $\left(\mathrm{f}^{2}=0.395, \mathrm{p}<0.01\right)$ orta düzeyde etkilemektedir.

\section{Hipotezlerin doğrulanması}

H1a, H1b, H1c, H3, H5a, H5b, H5c hipotezlerine ilişkin yol katsayıları (korelasyon değerleri), t değerleri, p değerlerini veren yol (path) analizi sonuçları Tablo 6' da yer almaktadır. Yol analizi, hipotezler aracilığı ile kurulan ilişkilerin model tarafından da desteklenip desteklenmediğini göstermektedir. Her bir hipotez için yol katsayısı değerlerine ait $t$ değerleri \%95 güven aralığına ait $t$ tablo değeri olan 1.96 'dan büyüktür. Ayrıca yol katsayısı değerlerinin p değerleri 0.01'den küçüktür (Çakır, 2019).

Tablo 6. Hipotezler için yol katsayıları ve test sonuçları

\begin{tabular}{|l|l|l|l|l|l|}
\hline & Yol - Doğrudan Etki & $\boldsymbol{\beta}$ & $\mathbf{t}$ & $\mathbf{p}$ & Karar \\
\hline H1a & PL-->AN & 0.737 & 19.195 & $0.000^{*}$ & Kabul \\
\hline H1b & PL-->GE & 0.245 & 3.070 & $0.002^{*}$ & Kabul \\
\hline H1c & PL-->TE & 0.348 & 4.821 & $0.000^{*}$ & Kabul \\
\hline H3 & AN-->TA & 0.682 & 15.776 & $0.000^{*}$ & Kabul \\
\hline H5a & TA-->GE & 0.476 & 6.251 & $0.000^{*}$ & Kabul \\
\hline H5b & TA--> TE & 0.433 & 6.271 & $0.000^{*}$ & Kabul \\
\hline H5c & TA-->BA & 0.532 & 8.994 & $0.000^{*}$ & Kabul \\
\hline${ }^{*}$ p<0.01 düzeyinde anlaml & \multicolumn{3}{|l}{} \\
\hline
\end{tabular}

Tablo 6.'daki değerlere göre bu modelde (Şekil 2) yer alan H1a hipotezi kabul edilmiştir ( $\beta=0.737$, $\mathrm{t}=19.195, \mathrm{p}<0.01)$, PL değişkeni, AN değişkenini pozitif yönde etkilemektedir. Benzer şekilde, H1b hipotezi kabul edilmiştir $(\beta=0.245, \mathrm{t}=3.070, \mathrm{p}<0.01)$, PL değişkeni, GE değişkenini pozitif yönde etkilemektedir. H1c hipotezi kabul edilmiştir $(\beta=0.348, \mathrm{t}=4.821, \mathrm{p}<0.01)$, PL değişkeni, TE değişkenini pozitif yönde etkilemektedir. H3 hipotezi kabul edilmiştir $(\beta=0.682, t=15.776, p<0.01)$, AN değişkeni, TA değişkenini pozitif yönde etkilemektedir.

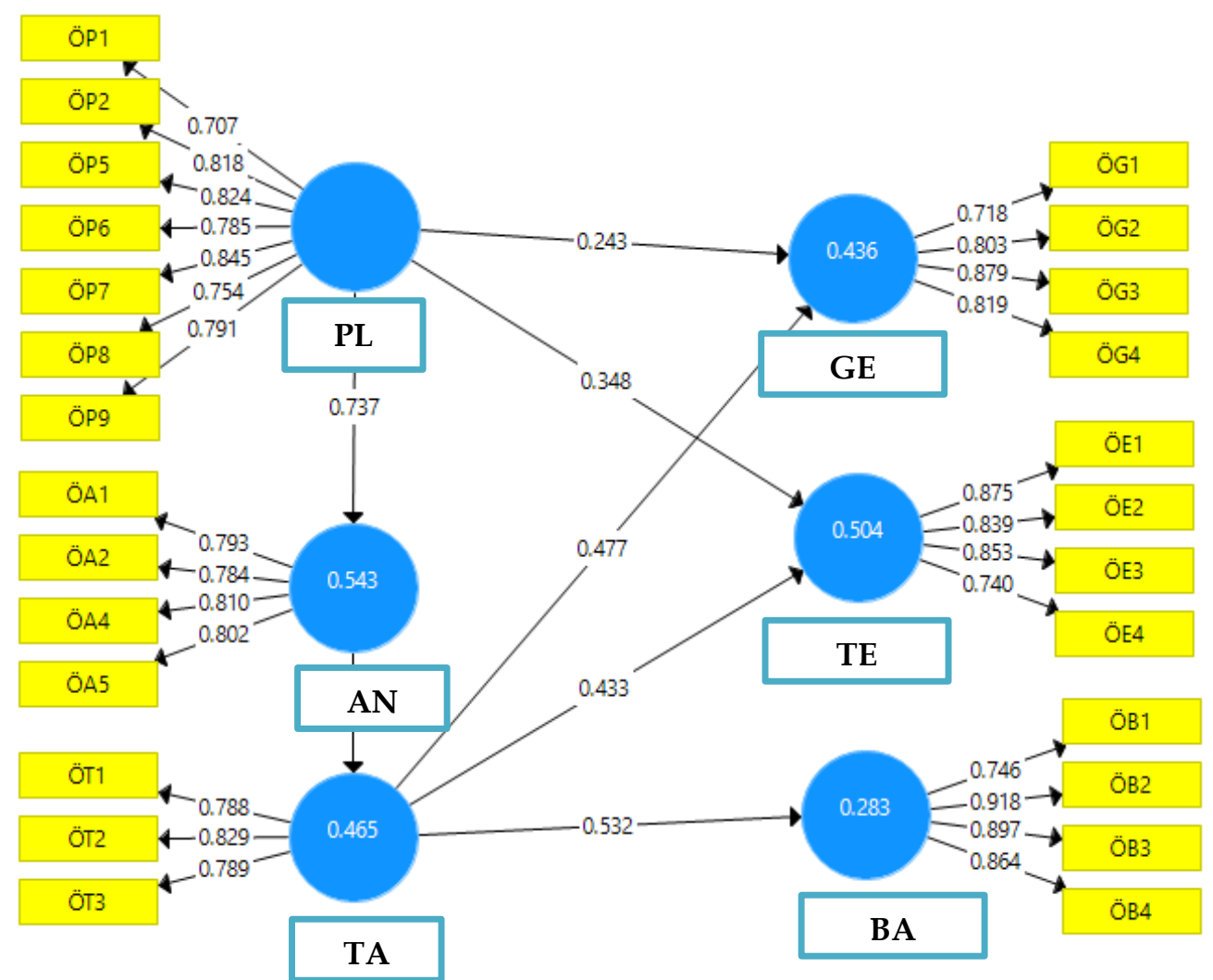

Şekil 2: Araştırma modelinin ayrıntılı PLS-SEM diyagramı 
H5a hipotezi kabul edilmiştir ( $\beta=0.476, t=6.251, p<0.01)$, TA değişkeni, GE değişkenini pozitif yönde etkilemektedir. H5b hipotezi kabul edilmiştir $(\beta=0.433, t=6.271, p<0.01)$, TA değişkeni, TE değişkenini pozitif yönde etkilemektedir. H5c hipotezi kabul edilmiştir $(\beta=0.532, t=8.994, p<0.01)$, TA değişkeni, BA değişkenini pozitif yönde etkilemektedir.

\section{Değişkenler arasındaki aracılık etkisi}

Değişkenler arasındaki aracılık etkisini tespit etmek amacıyla H2a, H2b, H2c, H2d, H4a, H4b ve H4c hipotezleri oluşturulmuştur. Bu hipotezler test edilmiş, elde edilen sonuçlar Tablo 7.'de ve Tablo 8.'de belirtildiği şekildedir. $\beta_{(a)}$, ilk değişken ile ikinci değişken arasındaki yol katsayısı değeri, $\beta_{(\mathrm{b})}$ ikinci değişken ile üçüncü değişken arasındaki yol katsayısı değeri, $\beta_{(c)}$ birinci değişken ile üçüncü değişken arasındaki yol katsayısı değerini belirtmektedir (Tablo 7). $\beta_{(\mathrm{d})}$ ise birinci değişken ile dördüncü değişken arasındaki yol katsayısı değerini ifade etmektedir (Tablo 8). Değişkenler arasındaki aracılık etkisi VAF (Variance Account For) değeri hesaplanarak bulunmuştur. Preacher ve Hayes'e (2008) göre VAF değeri dolaylı etkinin toplam etkiye oranını vermektedir ve bu değer hesaplanırken $\mathrm{VAF}=($ Dolaylı etki/Toplam Etki)*100 formülü kullanılmaktadır. VAF değeri 0.20 'nin altında ise değişkenler arasında aracılık etkisinin olmadığı, $0.20-0.80$ arasında ise kısmi aracılık etkisinin olduğu, 0.80 ' den büyük ise tam aracılık etkisinin olduğu bilinmektedir (Hair vd., 2011; Hair vd, 2016).

H4a, H4b, H4c hipotezlerinde TA değişkeninin diğer değişkenler üzerindeki aracılık etkisi incelenmektedir. Buna göre (Tablo 7) TA değişkeni, AN ve BA arasında kısmi aracıllk etkiye sahiptir (H4a: VAF=0.65, p<0.01). Benzer şekilde TA değişkeni, AN ve GE arasında kısmi aracıllk etkiye (H4b: $\mathrm{VAF}=0.68$, $\mathrm{p}<0.01$ ), ve AN ve TE arasında kısmi aracilı etkiye sahiptir (H4c: VAF=0.42, $\mathrm{p}<0.01$ ).

Tablo 7. TA için aracılık etkisi, yol katsayıları ve test sonuçları

\begin{tabular}{|c|c|c|c|c|c|c|c|}
\hline & Yol - Aracılık Etkisi & $\beta_{(\mathrm{a})}$ & $\beta_{(b)}$ & $\boldsymbol{\beta}_{(\mathrm{c})}$ & $\mathrm{p}$ & VAF & Karar \\
\hline $\mathrm{H} 4 \mathrm{a}$ & AN-->TA-->BA & 0.682 & 0.532 & 0.363 & $0.000^{*}$ & 0.65 & Kabul/Kısmi \\
\hline $\mathrm{H} 4 \mathrm{~b}$ & AN-->TA-->GE & 0.682 & 0.477 & 0.325 & $0.000^{*}$ & 0.68 & Kabul/Kısmi \\
\hline $\mathrm{H} 4 \mathrm{c}$ & AN-->TA--> TE & 0.682 & 0.433 & 0.295 & $0.000^{*}$ & 0.42 & Kabul/Kısmi \\
\hline
\end{tabular}

AN ve TA değişkenlerinin, PL ve BA değişkenleri arasında kısmi düzeyde çoklu aracılık etkisi bulunmaktadır (H2a: VAF=0.34, $\mathrm{t}=6.127, \mathrm{p}<0.01$ ). Benzer şekilde, $\mathrm{PL}$ ve $\mathrm{GE}$ değişkenleri arasında kısmi düzeyde çoklu aracilık etkisi (H2b: $\mathrm{VAF}=0.36, \mathrm{t}=5.016, \mathrm{p}<0.01)$ bulunmaktadır. PL ve TE değişkenleri arasında kısmi düzeyde çoklu aracılık etkisi bulunmaktadır (H2d: VAF=0.38, t=5.072, $\mathrm{p}<0.01)$. Ayrıca, AN değişkeni PL ve TA değişkenleri arasında kısmi aracılık etkiye sahiptir (H2c: VAF=0.59, $\mathrm{t}=10.491$, p<0.01). H2a, H2b, H2c, H2d hipotezleri için elde edilen yol katsayıları ve test sonuçları Tablo 8.'de belirtildiği şekildedir.

Tablo 8. AN ve TA için aracılık etkisi, yol katsayıları ve test sonuçları

\begin{tabular}{|l|l|c|c|c|c|c|c|l|}
\hline & Yol - Aracıllk Etkisi & $\boldsymbol{\beta}_{(\mathbf{a})}$ & $\boldsymbol{\beta}_{(\mathbf{b})}$ & $\boldsymbol{\beta}_{(\mathbf{c})}$ & $\boldsymbol{\beta}_{(\mathrm{d})}$ & $\mathbf{p}$ & VAF & Karar \\
\hline H2a & PL-->AN-->TA-->BA & 0.737 & 0.682 & 0.532 & 0.267 & $0.000^{*}$ & 0.34 & Kabul/K1smi \\
\hline H2b & PL-->AN-->TA-->GE & 0.737 & 0.682 & 0.477 & 0.240 & $0.000^{*}$ & 0.36 & Kabul/K1smi \\
\hline H2c & PL-->AN-->TA & 0.737 & 0.682 & 0.502 & - & $0.000^{*}$ & 0.59 & Kabul/K1smi \\
\hline H2d & PL-->AN-->TA--> TE & 0.737 & 0.682 & 0.433 & 0.218 & $0.000^{*}$ & 0.38 & Kabul/K1smi \\
\hline * p<0.01 düzeyinde anlaml
\end{tabular}

Yapısal eşitlik modellerinde değişkenler arasındaki aracılık etkinin anlamlı olup olmadığını test etmek amaciyla Sobel testi (Sobel, 1982; Preacher ve Leonardelli, 2010) uygulanmış, elde edilen bulgulara göre H4a $(\mathrm{z}=7.79405442, \mathrm{p}<0.01)$ ve $\mathrm{H} 2 \mathrm{c}(\mathrm{z}=11.98437497, \mathrm{p}<0.01)$ hipotezleri istatistiksel olarak anlaml bulunurken, H4b ( $z=5.68863744, p>0.01), H 4 c \quad(z=5.74511559, p>0.01)$ hipotezleri istatistiksel olarak anlamlı bulunmamıştır. Preacher ve Leonardelli'e (2010) göre Sobel testi yalnızca büyük örneklerde işe yaramaktadır. Bu testin yalnızca araştırmacının birincil verilere erişiminin olmadığ durumlarda kullanılması önerilmektedir. Araştırmacı birincil verilere sahipse, Bootstrapping yönteminin daha iyi bir alternatif olduğu belirtilmektedir (Preacher ve Leonardelli, 2010). Bu araştırmada araştırmacı birincil verilere sahiptir ve Tablo 7.'de ve Tablo 8.'de sunulan analiz sonuçları SmartPLS programında Bootstrapping analizi sonucu elde edilmiştir. Bu sonuçlara göre değişkenler arasındaki aracılık etkinin incelendiği H4a, H4b, H4c, H2a, H2b, H2c, H2d hipotezleri kabul edilmiştir ve istatistiksel olarak anlamlidir.

\section{Sonuç ve tartişma}

ERP sistemi uygulama aşamaları, geleneksel SDLC süreçleri ile paralellik göstermektedir ve ERP uygulama projelerinde her iki yaklaşım iç içe geçmiş bir şekilde birlikte kullanılabilir. Bu araştırmada SDLC bakış açısı ile ERP uygulama öncesi gerçekleştirilmesi gereken iş uygulamaları için bir model önerilmiş, bu modelin geçerliliği ve güvenirliliği test edilmiştir. Önerilen model SDLC'nin Planlama, 
Analiz, Tasarım, Gerçekleştirme, Test \& Entegrasyon ve Bakım süreçleri için ayrı ayrı incelenmiş ve bu süreçlerin birbirlerine etkisi ve birbirlerini ne ölçüde desteklediği değerlendirilmiştir.

ERP uygulama öncesi aşama sadece ERP yazılımı, satıcılar ve danışman seçme konularını içermemektedir. Özellikle "Planlama" süreci bu aşamada kritik öneme sahip bir süreçtir. Elde edilen bulgulara göre, ERP uygulama öncesi "Planlama" süreci, "Analiz" sürecinde 0.74, "Gerçekleştirme" sürecinde 0.25 , "Test ve Entegrasyon" sürecinde 0.35 birimlik pozitif yönde bir etkiye sahiptir. Grenci ve Hull'a (2020) göre SDLC'nin ilk aşaması olan planlama sürecinde yaşanan problemler sonraki aşamaları da olumsuz yönde etkilemektedir. Hustad ve Olsen (2011) çalışmasında ERP uygulama öncesi uygulamaların, sistem hakkında yüksek düzeyde bilgi ve yeterlilik gerektirdiğini, proje yöneticileri, ERP sağlayıcı firma yetkilisi ve danışmanların yer aldığı müzakere süreçleri gerektiren zorlu bir süreç olduğunu belirtmektedir.

"Planlama" sürecine benzer şekilde, ERP uygulama öncesi "Analiz" süreci, "Tasarım" sürecinde 0.68 birimlik pozitif yönde bir etkiye sahiptir. "Tasarım" süreci ise, "Gerçekleştirme" sürecinde 0.48, "Test ve Entegrasyon" sürecinde 0.43 , "Bakım" sürecinde 0.53 birimlik pozitif yönde bir etkiye sahiptir. Analiz süreci bir ERP uygulamasında en önemli süreçlerden biridir. Analiz sürecinden sonra gelen tasarım süreci, analiz sürecinde toplanan bilgilerin mantıksal olarak bir araya getirildiği bir süreçtir (Mudiraj; 2017). Bu nedenle bu süreçler kendisinden sonra gelen süreçlerdeki uygulamaları etkilemekte ve daha ileriki uygulamalara kısmen de olsa aracılık etmektedir.

Araştırmada ayrıca "Tasarım" ve "Analiz" süreçlerinin diğer süreçler arasındaki aracılık etkisi incelenmiştir. Elde edilen bulgulara göre ERP uygulama öncesi "Tasarım" süreci, "Analiz" ile "Bakım", "Analiz" ile "Gerçekleştirme", "Analiz" ile "Test ve Entegrasyon" süreçleri arasında kısmi aracılık etkisine sahiptir. Benzer şekilde ERP uygulama öncesi "Analiz" ve "Tasarım" süreçleri, birlikte, "Planlama" ile "Bakım", "Planlama" ile "Gerçekleştirme", "Planlama" ile "Test ve Entegrasyon" süreçleri arasında kısmi aracılık etkisine sahiptir. Ayrıca "Analiz" süreci, tek başına, "Planlama" ile "Tasarım" süreçleri arasında aracılık etkisi yapmaktadır.

ERP projelerinin uygulama öncesi aşaması için elde edilen bu sonuçlar, ERP projelerinin olası başarısı üzerinde kritik bir etkiye sahip olabilir. Bu çerçevede, ileri araştırmalarda ERP'nin kullanıcılar ve uygulayıcılar üzerindeki etkisini açıklayacak bir araştırma çerçevesi oluşturulabilir. Ayrıca ERP projelerinin uygulama öncesi aşaması için sektörel bazda örnek olay çalışmaları ile önerilen model sektörel bağlamda deneysel olarak test edilebilir. Bu araştırmanın bulguları öncülüğünde gerçekleştirilecek sektörel bazlı bir gereksinim analizi (ERP uygulama öncesi için), çevik yaklaşımla birleştirilerek Türkiye'deki ERP uygulama projelerine uygulandığında, uygulayıcıların ve araştırmacıların işletmelerdeki olası değişim sürecini kapsamlı bir şekilde keşfetmelerine yardımcı olabilir. Bu çalışma, ERP uzmanları, ERP proje yöneticileri, ERP departman yöneticileri, ERP uygulama mühendisleri için yararlı olabilir ve daha fazla araştırma için ERP uygulama aşaması ve uygulama sonrası için keşfedici bir bağlantı sağlayabilir.

ERP projelerinin uygulama öncesi aşamasının, ERP projelerinin genel başarısı üzerinde kritik bir etkiye sahip olduğu bilinmektedir. Bu nedenle bu çalışma, sadece ERP projelerinin uygulama öncesi aşaması için SDLC perspektifinden bir bakış sunmaktadır. Ancak, SDLC'nin ERP uygulama projelerinin farklı aşamalarındaki etkisini incelemek için daha fazla araştırmaya ihtiyaç duyulmaktadır. Ayrıca bu çalışmanın örneklemini farklı sektörlerden sınırlı sayıda kişi oluşturmaktadır. ERP projeleri sektörel bazda farklı gereksinimler gerektirir. Hatta bu gereksinimler modül bazlı olarak sınıflandırılabilir. Bu farklılıkları bu çalışmada görmek mümkün değildi. İleriye yönelik araştırmalarda, bu çalışma belirli bir sektör özelinde; örneğin imalat, otomotiv, inşaat, metal işleme, enerji, inşaat, telekomünikasyon, BT, perakende, yiyecek ve içecek gibi, yeniden geliştirilmeye açıktır.

\section{Hakem Değerlendirmesi / Peer-review:}

Dış bağımsız

Externally peer-reviewed

\section{Çıkar Çatışması / Conflict of interests:}

Yazar(lar) çıkar çatışması bildirmemiştir.

The author(s) has (have) no conflict of interest to declare. 


\section{Finansal Destek / Grant Support:}

Yazar bu çalışma için finansal destek almadığını beyan etmiştir.

The author declared that this study has received no financial support.

\section{Kaynakça / References}

Abdinnour, S., \& Saeed, K. (2015). User perceptions towards an ERP system. Journal of Enterprise Information Management, 28(2), 243-259.

Afthanorhan, W. M. A. B. W. (2014). Hierarchical component using reflective-formative measurement model in partial least square structural equation modeling (PLS-SEM). International Journal of Mathematics, 2(2), 33-49.

Ahmad, R. M. T. R. L., Othman, Z., \& Mukhtar, M. (2011). Campus ERP implementation framework for private institution of higher learning environment in Malaysia. WSEAS Transactions on advances in engineering education, 1(8), 1-12.

Balaji, S., \& Murugaiyan, M. S. (2012). Waterfall vs. V-Model vs. Agile: A comparative study on SDLC. International Journal of Information Technology and Business Management, 2(1), 26-30.

Bento, F., \& Costa, C. J. (2013). ERP measure success model; a new perspective. In Proceedings of the 2013 International Conference on Information Systems and Design of Communication (pp. 16-26).

Brunner, M., \& SÜ $\beta$, H. M. (2005). Analyzing the reliability of multidimensional measures: An example from intelligence research. Educational and Psychological Measurement, 65(2), 227-240.

Chadhar, M. A., \& Daneshgar, F. (2018). Organizational Learning and ERP Post-implementation Phase: A Situated Learning Perspective. Journal of Information Technology Theory and App., 19(2), 139-156.

Capaldo, G., \& Rippa, P. (2009). A planned-oriented approach for EPR implementation strategy selection. Journal of Enterprise Information Management, 22(6), 642-659.

Çakır, F. S. (2019). Kısmi En Küçük Kareler Yapısal Eşitlik Modellemesi (PLS-SEM) ve Bir Uygulama. Sosyal Araştırmalar ve Davranış Bilimleri, 5(9), 111-128.

Dearing, J. W., \& Cox, J. G. (2018). Diffusion of innovations theory, principles, and practice. Health Affairs, 37(2), 183-190.

Davenport, T. H., \& Short, J. E. (1990). The new industrial engineering: information technology and business process re-design. Sloan Management Review, 31(4), 11-27.

Ehie, I. C., \& Madsen, M. (2005). Identifying critical issues in enterprise resource planning (ERP) implementation. Computers in industry, 56(6), 545-557.

Fink, A., \& Litwin, M. S. (1995). How to measure survey reliability and validity (Vol. 7). Sage.

Fornell, C., Larcker, D. F. (1981). Evaluating Structural Equation Models with Unobservable Variables and Measurement Error. Journal of Marketing Research, 18(1), 39-50.

Geisser, S. (1974). A predictive approach to the random effect model. Biometrika, 61(1), 101-107.

Grenci, R. T., \& Hull, B. Z. (2020). New dog, old tricks: ERP and the systems development life cycle. Journal of Information Systems Education, 15(3), 7.

Hair, J. F., Ringle, C. M., \& Sarstedt, M. (2011). PLS-SEM: Indeed a silver bullet. Journal of Marketing theory and Practice, 19(2), 139-152.

Hair, J. F., Ringle, C. M., \& Sarstedt, M. (2013). Partial least squares structural equation modeling: Rigorous applications, better results and higher acceptance. Long range planning, 46(1-2), 1-12.

Hair Jr, J. F., Hult, G. T. M., Ringle, C., \& Sarstedt, M. (2016). A primer on partial least squares structural equation modeling (PLS-SEM). Sage publications.

Hair, J. F., Matthews, L. M., Matthews, R. L., \& Sarstedt, M. (2017). PLS-SEM or CB-SEM: updated guidelines on which method to use. International Journal of Multivariate Data Analysis, 1(2), 107-123. 
Hasibuan, Z. A., \& Dantes, G. R. (2012). Priority of key success factors on enterprise resource planning (ERP) system implementation life cycle. Journal of Enterprise Resource Planning Studies. https://ibimapublishing.com/articles/JERPS/2012/122627/

Handcock, M. S., \& Gile, K. J. (2011). Comment: On the concept of snowball sampling. Sociological Methodology, 41(1), 367-371.

Henseler, J., Ringle, C.M., \& Sinkovics, R.R. (2009). The use of partial least squares path modeling in international marketing. In Sinkovics, R.R. and Ghauri, P.N. (Ed.) New Challenges to International Marketing (Advances in International Marketing, Vol. 20), Emerald Group Publishing Limited, Bingley, pp. 277-319.

Huang, T. (2016). Peeking at the ERP Decline stage: Japanese empirical evidence. Computers in Industry, 82, 224-232.

Huang, T., \& Yasuda, K. (2014). ERP life cycle models: an annotated bibliographic review. In Proceedings of the 15th Asia Pacific Industrial Engineering and Management Systems Conference (pp. 70-77).

Huang, T., \& Yasuda, K. (2016). Reinventing the ERP life cycle model: from go-Live to withdrawal. Journal of Enterprise Resource Planning Studies, 2016, 1-21.

Hustad, E., \& Olsen, D. H. (2011). Exploring the ERP pre-implementation process in a small-andmedium-sized enterprise: a case study of a Norwegian retail company. ECIS 2011 Proceedings. 8. http://aisel.aisnet.org/ecis2011/8

Kanellou, A., \& Spathis, C. (2013). Accounting benefits and satisfaction in an ERP environment. International Journal of Accounting Information Systems, 14(3), 209-234.

Kline, R. B. (2015). Principles and practice of structural equation modeling. Guilford publications.

Kwon, T. H., \& Zmud, R. W. (1987). Unifying the fragmented models of information systems implementation. In Critical issues in information systems research (pp. 227-251).

Mahmud, I., Ramayah, T., \& Kurnia, S. (2017). To use or not to use: Modelling end user grumbling as user resistance in pre-implementation stage of enterprise resource planning system. Information Systems, 69, 164-179.

Marnewick, C., \& Labuschagne, L. (2005). A conceptual model for enterprise resource planning (ERP). Information management $\mathcal{E}$ computer security, 13(2), 144-155.

Meissonier, R., \& Houzé, E. (2010). Toward an 'IT Conflict-Resistance Theory': action research during IT pre-implementation. European Journal of Information Systems, 19(5), 540-561.

Mudiraj, A. R. (2014). BPR: The First Step for ERP Implementation. Int. Res. J. Commerce, Business Social Sciences (IRJCBSS), 2(13), 1-2.

Mudiraj, A. R. (2017). Study on Critical Factors affecting on ERP implementation process. International Journal of Recent Trends in Engineering and Research, 3(6), 177-181.

Nizam, A. (2015). Yazılım Proje Yönetimi. İstanbul: Papatya Yayıncılık.

Panorama Consulting (2020). The 2020 ERP Report.https:/ / www.panorama-consulting.com/resourcecenter/2020-erp-report/(Erişim Tarihi: 22.12.2020).

Peng, G. C., \& Nunes, M. B. (2009). Identification and assessment of risks associated with ERP postimplementation in China. Journal of Enterprise Information Management, 22(5), 587-614.

Preacher, K. J. \& Leonardelli, G.J. (2010). Calculation for the Sobel test: An interactive calculation tool for mediation tests. http://quantpsy.org/sobel/sobel.htm (Erişim Tarihi:23.12.2020).

Preacher, K. J., \& Hayes, A. F. (2008). Asymptotic and resampling strategies for assessing and comparing indirect effects in multiple mediator models. Behavior research methods, 40(3), 879-891.

Ringle, C. M., Wende, S., and Becker, J. M. (2015). "SmartPLS 3." Boenningstedt: SmartPLS GmbH, http://www.smartpls.com

Rogers, E. M. (2004). A prospective and retrospective look at the diffusion model. Journal of health communication, 9(S1), 13-19.

Ruivo, P., Oliveira, T., \& Neto, M. (2014). Examine ERP post-implementation stages of use and value: Empirical evidence from Portuguese SMEs. International Journal of Accounting Information Systems, 15(2), 166-184. 
Sobel, M. E. (1982). Asymptotic confidence intervals for indirect effects in structural equation models. Sociological methodology, 13, 290-312.

Stone, M. (1974). Cross-validatory choice and assessment of statistical predictions. Journal of the Royal Statistical Society: Series B (Methodological), 36(2), 111-133.

Yılmaz, V., Yasemin, C. A. N., \& Nil, A. R. A. S. (2019). Kısmi En Küçük Kareler Yapısal Eşitlik Modellemesiyle (PLS-YEM) Nükleer ve Yenilenebilir Enerjiye İlişkin Tutumların Araştırılması. Alphanumeric Journal, 7(1), 87-102.

Wong, K. K. K. (2013). Partial least squares structural equation modeling (PLS-SEM) techniques using SmartPLS. Marketing Bulletin, 24(1), 1-32. 